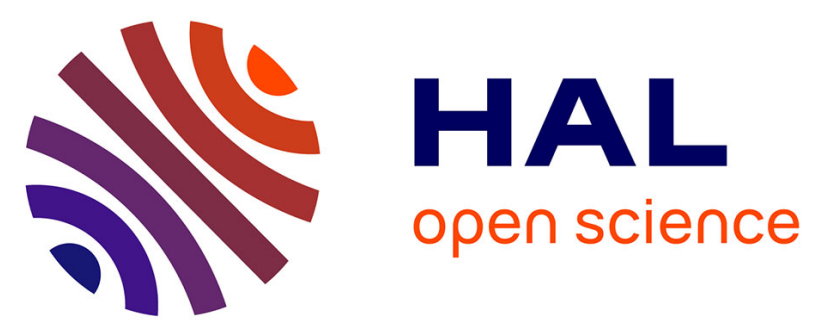

\title{
No clinically relevant CYP3A induction after St. John's wort with low hyperforin content in healthy volunteers
}

Silke C. Mueller, Jolanta Majcher-Peszynska, Ralf G. Mundkowski, Bernhard

Uehleke, Sebastian Klammt, Hartwig Sievers, Romanus Lehnfeld, Bruno

Frank, Kerstin Thurow, Guenther Kundt, et al.

\section{To cite this version:}

Silke C. Mueller, Jolanta Majcher-Peszynska, Ralf G. Mundkowski, Bernhard Uehleke, Sebastian Klammt, et al.. No clinically relevant CYP3A induction after St. John's wort with low hyperforin content in healthy volunteers. European Journal of Clinical Pharmacology, 2008, 65 (1), pp.81-87. 10.1007/s00228-008-0554-y . hal-00477921

\section{HAL Id: hal-00477921 \\ https://hal.science/hal-00477921}

Submitted on 30 Apr 2010

HAL is a multi-disciplinary open access archive for the deposit and dissemination of scientific research documents, whether they are published or not. The documents may come from teaching and research institutions in France or abroad, or from public or private research centers.
L'archive ouverte pluridisciplinaire HAL, est destinée au dépôt et à la diffusion de documents scientifiques de niveau recherche, publiés ou non, émanant des établissements d'enseignement et de recherche français ou étrangers, des laboratoires publics ou privés. 


\title{
No clinically relevant CYP3A induction after St. John's wort with low hyperforin content in healthy volunteers
}

\author{
Silke C. Mueller • Jolanta Majcher-Peszynska • \\ Ralf G. Mundkowski • Bernhard Uehleke • \\ Sebastian Klammt • Hartwig Sievers • \\ Romanus Lehnfeld • Bruno Frank • Kerstin Thurow • \\ Guenther Kundt $\cdot$ Bernd Drewelow
}

Received: 19 May 2008 /Accepted: 6 August 2008 / Published online: 3 September 2008

(C) Springer-Verlag 2008

\begin{abstract}
Objective Induction of CYP3A by St. John's wort (SJW) products with high hyperforin content is well described. Since CYP3A induction is mediated by hyperforin in a concentration-dependent manner, and SJW preparations differ significantly in hyperforin content, the aim of the
\end{abstract}

S. C. Mueller $(\bowtie) \cdot J$. Majcher-Peszynska • R. G. Mundkowski •

S. Klammt $\cdot$ B. Drewelow

Center of Pharmacology and Toxicology,

Institute of Clinical Pharmacology, University of Rostock,

Schillingallee 70 ,

18057 Rostock, Germany

e-mail: silke.mueller@med.uni-rostock.de

\section{G. Kundt}

Institute for Medical Informatics and Biometry,

University of Rostock,

Rembrandtstrasse 16/17,

18057 Rostock, Germany

B. Uehleke

Department of Naturopathy, Universitätsmedizin Berlin, CBF,

Hindenburgdamm 30,

12203 Berlin, Germany

B. Frank

Kneipp-Werke,

Steinbachtal 43

97064 Würzburg, Germany

H. Sievers $\cdot$ R. Lehnfeld

PhytoLab GmbH \& Co KG,

Dutendorfer Strasse 5-7,

91487 Vestenbergsgreuth, Germany

\section{K. Thurow}

Center for Life Science Automation, University of Rostock,

Friedrich-Barnewitz-Str. 8,

18119 Rostock, Germany study was to evaluate the effect of an SJW powder with low hyperforin content on CYP3A function.

Methods Twenty healthy male volunteers received an SJW powder with low hyperforin content for 2 weeks. Midazolam plasma concentration time profiles were characterized after a single oral dose of $7.5 \mathrm{mg}$ midazolam on the day before and on the 14th day of SJW medication.

Results Midazolam $\mathrm{AUC}_{0-\infty}$ slightly decreased from $124.0 \pm$ $62.5 \mathrm{ng} / \mathrm{ml} \cdot \mathrm{h}$ at baseline to $105.6 \pm 53.2 \mathrm{ng} / \mathrm{ml} \cdot \mathrm{h}$ after SJW $(P<0.05)$, representing a mean $11.3 \%$ decrease $(95 \%$ CI: -22.8 to 0.21 ). No significant change in midazolam $\mathrm{C}_{\max }, \mathrm{t}_{1 / 2}$ and $\mathrm{t}_{\max }$ was observed. For all pharmacokinetic parameters, the $90 \%$ CI for the geometric mean ratio of treatment over baseline were within the no-effect boundaries of $0.70-1.43$.

Conclusion Administration of an SJW product with low hyperforin content resulted in a mild induction of CYP3A not considered clinically relevant.

Keywords Hypericum · Hyperforin · CYP3A .

Drug interaction

\section{Introduction}

St. John's wort (Hypericum perforatum L.) preparations are popular herbal remedies used worldwide to treat mild depression as well as traditional symptoms such as nervous complaints, psychovegetative disturbances, and nervous unrest [1]. Various formulations (e.g., extracts, crude drug in tablets or capsules, tinctures, teas) in several doses are available either as over-the-counter drugs or dietary supplements. Like other herbal drugs, St. John's wort is a complex mixture containing a variety of constituents: the most 
abundant are hypericins, flavonoids, and hyperforin [2, 3]. There is still debate over which compounds form the active principle, which has been variably attributed to hyperforins, hypericins, and flavonoids [1-3]. It is also hypothesized that additive or synergistic actions of various compounds may be responsible for the herb's therapeutic effects [4] and that the total herbal drug preparation as a complex must be regarded as the active constituent or principle of St. John's wort [2].

The compositions of marketed St. John's wort products differ in the amount of pharmacologically active compounds, especially hyperforin. The hyperforin content of 33 different Hypericum products marketed in Germany ranged from $<0.5$ to $24.87 \mathrm{mg}$ per unit [5-9]. Clinical efficacy has been demonstrated in St. John's wort extracts with high hyperforin content but also in those with negligible hyperforin content [10-12].

Since 1999, safety concerns regarding the potential for drug interactions have arisen with the use of St. John's wort [6]. Clinically relevant drug interactions of Hypericum extracts have been reported in several case reports and drug interaction studies and have been systematically reviewed $[12,13]$. The underlying mechanism is an induction of mainly intestinal CYP3A and p-glycoprotein [14] leading to decreased plasma concentration and potential therapeutic failure of substrates of CYP3A and p-glycoprotein. In vitro investigations have demonstrated that CYP3A induction is mediated by an interaction of hyperforin with the pregnane $X$ receptor [15-17]. Furthermore, this reaction was dosedependent and not comparably achievable by hypericins or flavonoids alone $[15,18]$. In vitro testing of CYP3A induction by six commercial St. John's wort extracts with a 62-fold variation in hyperforin content resulted in a significant correlation of magnitude of induction and hyperforin content, but no correlation with hypericins and flavonoids [17]. This agrees with the results of a drug interaction study with six St. John's wort preparations in healthy volunteers, where the decrease in oral midazolam exposure, used as a CYP3A phenotyping probe, was correlated with hyperforin dose, but not with hypericin dose [19].

As reviewed by Whitten et al. [12] and Madabushi et al. [6], most clinical studies investigating drug interactions by St. John's wort in general and specifically CYP3A induction used St. John's wort extracts with high hyperforin content. While the studies using hyperforin-rich St. John's wort extracts consistently reported clinically relevant interaction consistent with CYP3A induction, only a few studies with extracts with low hyperforin content have been performed [6, 12]. All of these studies using either alprazolam, ethinyl estradiol, or cyclosporine A as CYP3A substrates demonstrated no significant effect on CYP3A $[12,20,21]$.
To draw general conclusions, however, regulatory authorities suggest studies using the most sensitive substrate. If the investigational drug is suspected to be an inducer of CYP3A, an initial clinical study using oral midazolam as the most sensitive substrate for CYP3A is suggested. If this study were to show negative results, it could be presumed that less sensitive substrates would be unaffected, and no further studies would be needed [22]. In an exploratory study using midazolam as probe substrate, six St. John's wort preparations with different compositions of main constituents, especially hyperforin, have been found to induce CYP3A to different extents [19]. The extent of CYP3A induction was correlated with hyperforin dose. While the St. John's wort extract with the highest content of hyperforin clearly resulted in a clinically relevant CYP3A induction with $80 \%$ decrease in midazolam exposure, the products with the lowest hyperforin content resulted only in a minor $21 \%$ midazolam AUC decrease [19].

Since the marketed St. John's wort products differ considerably in hyperforin content and available data suggest that St. John's wort products with low hyperforin content could lack clinically relevant CYP3A induction or have decreased CYP3A induction potential, the aim of this study was to investigate the effect of a St. John's wort product with a known low hyperforin content on CYP3A function using midazolam as probe substrate.

\section{Methods}

\section{Subjects}

Twenty healthy male non-smoking volunteers with a mean age of $24.9 \pm 2.3$ years, a height of $183 \pm 7.1 \mathrm{~cm}$, a weight of $78.2 \pm 8.4 \mathrm{~kg}$, and a body mass index of $23.2 \pm 1.9 \mathrm{~kg} / \mathrm{m}^{2}$ were enrolled in the study. Participants were determined to be healthy on the basis of medical history, physical examination, electrocardiogram, and routine urine, clinicalchemical, and hematologic screening. Furthermore, all volunteers were required to have no laboratory evidence of hepatitis $\mathrm{B}$, hepatitis $\mathrm{C}$, or human immunodeficiency virus infection.

Participants were excluded if they had any relevant medical history, a history of acute infection within the 4 weeks before admission, use of an investigational drug or study participation within 2 months prior to admission to this study, or use of any prescription or over-the-counter drug (including herbal medicines) within 4 weeks before enrollment or during the study.

One week before the start of the study and during the study the participants were not allowed to eat grapefruit or drink grapefruit-containing beverages, alcohol or herbal 
teas. Furthermore, all volunteers had to keep a diary of all their meals and beverages during the study period.

All subjects gave written informed consent before enrollment in the study. The study began after receiving approval by the ethics committee of the University of Rostock and was performed according to national law of Germany.

\section{Study design}

The study was an open-label one-sequence crossover, single-dose (midazolam)/multiple-dose (St. John's wort) drug-drug interaction study. On the day before starting St. John's wort medication, baseline pharmacokinetics of midazolam were evaluated. On day 14 of the St. John's wort medication period, a second midazolam pharmacokinetic characterization was performed. Both midazolam pharmacokinetic study days were conducted identically. After an overnight fast, volunteers received one tablet of $7.5 \mathrm{mg}$ midazolam (Dormicum 7.5 Lacktabletten, batch no. B152801/12; Hoffmann-La Roche AG, Basel, Switzerland) together with $200 \mathrm{ml}$ water. Blood samples were taken through a venous catheter before administration of midazolam and at 5, 10, 15, 20,30, and $50 \mathrm{~min}$ and 1, 1.5, 2, $2.5,3,4,6,8$, and $12 \mathrm{~h}$ after ingestion of midazolam. During the study day, volunteers were allowed to drink water starting $2 \mathrm{~h}$ after midazolam ingestion. Furthermore, an identical light lunch was served $4 \mathrm{~h}$ and an identical light supper $10 \mathrm{~h}$ after they had taken midazolam.

\section{Study medication}

Volunteers received St. John's wort as capsules containing 500 mg Hyperici herba (Pharmacopoea Europaea) powder and had to take two capsules per day, one capsule in the morning and one capsule in the evening for 14 days. The capsules (batch no. 40228) were provided by Kneipp Werke, Würzburg, Germany. The contents of the main St. John's wort constituents (hyperforin, total hypericins, and flavonoids) per capsule were analyzed independently from the manufacturer in 10 randomly selected capsules. All study medication was stored in the refrigerator $\left(4^{\circ} \mathrm{C}\right)$ until release to the study participants.

Analysis of St. John's wort constituents in capsules

Analysis of the St. John's wort main constituents in the capsules was performed as described previously [19]. Hyperforin (adhyperforin plus hyperforin) was determined by HPLC as previously described [5]. Total hypericin (hypericin and pseudohypericin) was determined by HPLC according to Gaedcke [23]. The total flavonoid content (calculated as rutin) was determined by reverse-phase HPLC as previously described [24].
Midazolam analysis

Midazolam plasma levels were determined by GC/MS analysis with minor modifications as described previously $[19,25]$. GC was performed in splitless mode $(60 \mathrm{~s}$, then split 1:20) at an inlet temperature of $280^{\circ} \mathrm{C}$ using a $19091 \mathrm{~S}-$ 433 capillary column $30 \mathrm{~m} \times 0.25 \mathrm{~mm}, 0.25-\mu \mathrm{m}$ film thickness (Agilent Technologies) with helium as carrier gas at a constant flow rate of $1.0 \mathrm{ml} / \mathrm{min}$ and a temperature gradient starting at $80^{\circ} \mathrm{C}(2 \mathrm{~min})$, increased at $40^{\circ} \mathrm{C} / \mathrm{min}$ to $280^{\circ} \mathrm{C}$, then at $25^{\circ} \mathrm{C} / \mathrm{min}$ to $320^{\circ} \mathrm{C}(2 \mathrm{~min})$. Midazolam and diazepam (IS) were detected by positive EI $(70 \mathrm{eV}) \mathrm{MS}$ scanning $\mathrm{m} / \mathrm{z} 220-340$ per $0.1 \mathrm{~s}$ at retention times of $8.5 \mathrm{~min}(\mathrm{~m} / \mathrm{z} 310$; qualifier traces $312,325,327)$ and $8.1 \min (256,283,284)$, respectively. The assay was validated according to international guidelines $[26,27]$ with recoveries of $75-85 \%$ and an LLoQ for midazolam of $1.0 \mu \mathrm{g} / \mathrm{L}$ (inter-/intraday RE and $\mathrm{CV}-10.8 /-7.3$ and $5.4 /$ $4.8 \%$, respectively).

\section{Pharmacokinetic analysis}

Pharmacokinetic parameters of midazolam were calculated by noncompartmental analysis with Kinetika 4.2 (Inna Phase, Philadelphia, PA, USA). Midazolam area under the curve from time 0 to $12 \mathrm{~h}\left(\mathrm{AUC}_{0-12 \mathrm{~h}}\right)$ was calculated by use of the linear trapezoidal rule. The terminal rate constant $(\lambda z)$ was estimated by log-linear regression using at least the last four concentration-time points $\left(R^{2}>0.95\right)$. Elimination half-life $\left(\mathrm{t}_{1 / 2}\right)$ was calculated using $\mathrm{t}_{1 / 2}=0.693 /$ $\lambda z \cdot \mathrm{AUC}_{0-\infty}$ was calculated as follows: $\mathrm{AUC}_{0-\mathrm{t}}+\mathrm{C}_{\text {last }} / \lambda \mathrm{z}$, where $\mathrm{C}_{\text {last }}$ is the last measurable data point. The apparent oral clearance $(\mathrm{Cl} / \mathrm{F})$ was determined by using the equation $\mathrm{Cl} / \mathrm{F}=$ dose $/ \mathrm{AUC}_{0-\infty}$. The maximum plasma concentration $\left(\mathrm{C}_{\max }\right)$ and the time to reach $\mathrm{C}_{\max }\left(\mathrm{t}_{\max }\right)$ were derived directly from the data.

\section{Statistical analysis}

First, descriptive statistics were computed for the pharmacokinetic variables. The statistics computed included mean and standard deviation (SD) of continuous variables, frequencies, and relative frequencies of categorical factors. Values before and after St. John's wort were compared by paired $t$-test. The relative differences in pharmacokinetic parameters after comedication with St. John's wort compared with baseline were evaluated as mean and 95\% confidence interval (CI). Moreover, 90\% CI of the geometric mean ratio of the treatment phase over the control phase was calculated to evaluate differences in pharmacokinetic parameters in the absence and presence of St. John's wort [22]. No-effect limits of $0.80-1.25$ have often been used by default. Due to the large inter- and 
intraindividual variability in CYP3A function, these limits have recently been discussed to be too conservative, and no-effect limits of $0.70-1.43$ have been proposed [28] and used [29]. Based on this, effects of the study medication on pharmacokinetic parameters were considered clinically irrelevant if the $90 \% \mathrm{CI}$ were within the equivalence limits of $0.70-1.43$. All $P$ values resulted from two-sided statistical tests, and $P \leq 0.05$ was considered to be significant.

Statistical analysis was performed by SPSS 15.0 for Windows (SPSS, Chicago, IL, USA).

\section{Results}

Subjects All volunteers completed the study and were evaluated for interaction. Compliance was estimated by pill counting (96-109\% of the expected tablets were taken from containers). Within the dietary diaries, no volunteer who consumed known or suspected CYP3A inhibitors or inducers, especially grapefruit, could be identified. Safety was evaluated by physical examination, electrocardiogram, and routine urine, clinical-chemical, and hematologic screening before and after the last study day and by symptom-guided adverse event monitoring. Overall, 21 adverse events were reported in 13 volunteers. All of the adverse events were mild and well described in the manufacturer's product information. No severe or unexpected adverse events were observed.

Content of main constituents in St. John's wort study medication The contents of hyperforin (adhyperforin plus hyperforin), total hypericins (hypericin plus pseudohypericin) and flavonoids (calculated as rutin) per capsule were total hyperforin $0.06 \pm 0.001 \mathrm{mg}$, total hypericins $0.60 \pm$ $0.03 \mathrm{mg}$, and total flavonoids $17.77 \pm 0.6 \mathrm{mg}$.

Midazolam pharmacokinetic parameters Mean concentration-time profiles of midazolam before and after treatment with St. John's wort are presented in Fig. 1. Midazolam exposure tended to be mildly decreased after St. John's wort treatment. Midazolam $\mathrm{AUC}_{0-12 \mathrm{~h}}$ decreased to $99.3 \pm$ 49.4 from $116.5 \pm 57.4 \mathrm{ng} / \mathrm{ml} \cdot \mathrm{h}$, and correspondingly midazolam AUC $_{0-\infty}$ decreased to $105.6 \pm 53.2$ from $124.0 \pm$ $62.5 \mathrm{ng} / \mathrm{ml} \cdot \mathrm{h}$ (both $P<0.05$ ). However, when related to individual baseline levels, midazolam $\mathrm{AUC}_{0-12 \mathrm{~h}}$ was reduced by $11.1 \%$ (95\% CI: -23.0 to 0.76$)$ and midazolam AUC $_{0-\infty}$ was reduced by $11.3 \%$ (95\% CI: -22.8 to 0.21$)$. Correspondingly, midazolam apparent oral clearance increased by $21.5 \%$ (95\% CI: $5.2-37.8)$. No significant changes were observed after St. John's wort treatment regarding midazolam $\mathrm{C}_{\max }, \mathrm{t}_{\max }$ and $\mathrm{t}_{1 / 2}(P>0.05$, see Table 1).

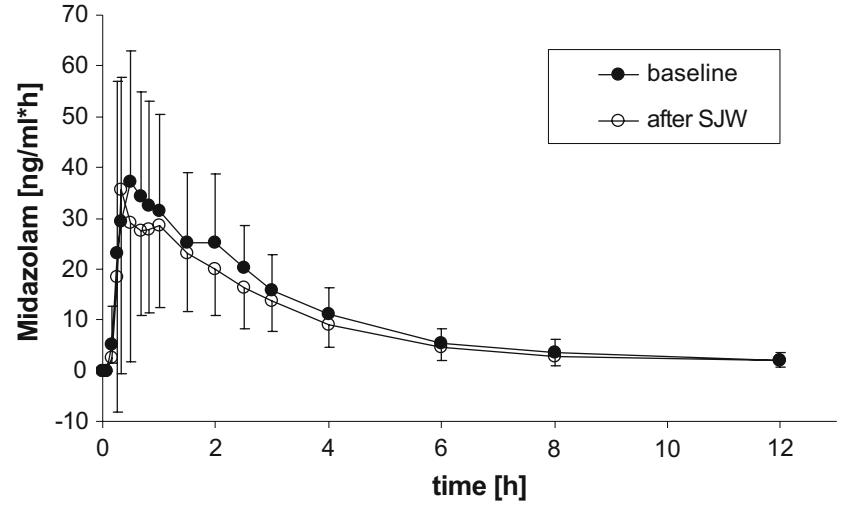

Fig. 1 Midazolam concentration-time data on the day before St. John's wort (baseline, solid circles) and after St. John's wort (on day 14 , open circles). Mean \pm standard deviation are shown; $n=20$

Ratio of midazolam during St. John's wort treatment phase over control phase The $90 \%$ CIs of the geometric mean ratio of midazolam $\mathrm{AUC}_{0-12 \mathrm{~h}}$, midazolam $\mathrm{AUC}_{0-\infty}, \mathrm{C}_{\max }$, $\mathrm{t}_{1 / 2}, \mathrm{t}_{\max }$, and $\mathrm{Cl} / \mathrm{F}$ during St. John's wort treatment phase over control (baseline) phase were calculated to evaluate whether they were contained within the equivalence limits of $0.70-1.43$ (Table 1). The $90 \%$ CIs of all pharmacokinetic parameters fell completely within the no-effect limits of $0.70-1.43$.

\section{Discussion}

In the study presented here, treatment with St John's wort powder capsules with low hyperforin content resulted in a significant but mild $11 \%$ decrease in midazolam AUC and a corresponding mild increase in midazolam oral clearance of $21 \%$. However, neither $\mathrm{C}_{\max }, \mathrm{t}_{1 / 2}$, nor $\mathrm{t}_{\max }$ of midazolam was significantly changed.

To evaluate if pharmacokinetic changes could have clinical relevance, pharmacokinetic drug-drug interactions are suggested to be treated as equivalence problems [22]. No-effect limits of $0.80-1.25$ are often used by default. Due to large within-subject variability of CYP3A function, this concept has been discussed to be too conservative and wider no-effect boundaries of $0.70-1.43$ have been applied $[28,29]$. Consistent with a lack of a clinically relevant induction of CYP3A by the St. John's wort powder with low hyperforin content evaluated in this study, the $90 \%$ CIs of the geometric mean ratios of treatment phase over baseline phase for all pharmacokinetic parameters were found to be completely within the no-effect limits of $0.70-1.43$.

In contrast, St. John's wort preparations with high hyperforin content consistently have shown clear evidence for CYP3A induction $[6,12,13]$. When oral midazolam was used as a CYP3A probe drug testing global (intestinal 
Table 1 Pharmacokinetic parameter values of midazolam before and after St. John's wort

\begin{tabular}{lllll}
\hline & $\begin{array}{l}\text { Baseline (mean } \pm \\
\mathrm{SD})\end{array}$ & $\begin{array}{l}\text { After SJW (mean } \pm \\
\mathrm{SD})\end{array}$ & $\begin{array}{l}\text { Mean \% change after SJW compared } \\
\text { to baseline [95\% CI] }\end{array}$ & $\begin{array}{l}\text { Ratio SJW phase/baseline (geometric } \\
\text { mean } \\
\text { point estimate [90\% CI]) }\end{array}$ \\
\hline $\mathrm{AUC}_{0-}$ & $116.5 \pm 57.4 \mathrm{ng} / \mathrm{ml} \cdot \mathrm{h}$ & $99.3 \pm 49.4 \mathrm{ng} / \mathrm{ml} \cdot \mathrm{h}^{*}$ & $-11.1[-23.0$ to 0.76$]$ & $0.85[0.76$ to 0.96$]$ \\
$12 \mathrm{~h}$ & & & & $0.85[0.77$ to 0.95$]$ \\
$\mathrm{AUC}{ }_{0-\infty}$ & $124.0 \pm 62.5 \mathrm{ng} / \mathrm{ml} \cdot \mathrm{h}$ & $105.6 \pm 53.2 \mathrm{ng} / \mathrm{ml} \cdot \mathrm{h}^{*}$ & $-11.3[-22.8$ to 0.21$]$ & $0.93[0.75$ to 1.18$]$ \\
$\mathrm{C}_{\max }$ & $48.5 \pm 29.8 \mathrm{ng} / \mathrm{ml}$ & $45.1 \pm 29.0 \mathrm{ng} / \mathrm{ml}$ & $10.5[-22.6$ to 43.7$]$ & $1.04[0.74$ to 1.34$]$ \\
$\mathrm{t}_{\max }$ & $1.09 \pm 0.74 \mathrm{~h}$ & $0.88 \pm 0.60 \mathrm{~h}$ & $4.06[-31.8$ to 39.9$]$ & $0.94[0.86$ to 1.03$]$ \\
$\mathrm{t}_{1 / 2}$ & $2.54 \pm 0.73 \mathrm{~h}$ & $2.36 \pm 0.59 \mathrm{~h}$ & $-3.59[-14.0$ to 6.79$]$ & $1.16[1.04$ to 1.30$]$ \\
$\mathrm{Cl} / \mathrm{F}$ & $1,224 \pm 514 \mathrm{ml} / \mathrm{min}$ & $1,420 \pm 541 \mathrm{ml} / \mathrm{min} *$ & $21.5[5.2$ to 37.8$]$ & \\
\hline
\end{tabular}

${ }^{*} P<0.05$ compared to baseline values with paired $t$-test

$S J W$ St. John's wort, $S D$ standard deviation, $C I$ confidence interval

and hepatic) CYP3A function, midazolam AUC was reduced by $79 \%$ [19] or $50 \%$ [30] 2 weeks after comedication with a hyperforin-rich St.John's wort product. This AUC reduction was accompanied by a $65 \%$ [19] or $53 \%$ [30] decrease in $\mathrm{C}_{\max }$, while midazolam $\mathrm{t}_{1 / 2}$ remained unchanged. This indicates that the interaction is mainly mediated by an induction of intestinal CYP3A, rather than hepatic CYP3A.

This was underlined in two studies that used oral (to test global, hepatic, and intestinal CYP3A) and intravenous (to test only hepatic CYP3A) midazolam in the same individuals in comedication with a hyperforin-rich St. John's wort. In these studies, the decrease in midazolam AUC or increase in midazolam clearance was 2-4 times greater after oral midazolam than after application of intravenous midazolam [30, 31]. Again, the decrease in midazolam AUC after oral application was accompanied by a decrease in midazolam $\mathrm{C}_{\max }$, while midazolam $\mathrm{t}_{1 / 2}$ remained unaffected [30, 31]. In contrast to this, the mild $11 \%$ decrease in midazolam AUC in this study using a St. John's wort product with low hyperforin content was accompanied by neither a change in $\mathrm{C}_{\max }$ nor $\mathrm{t}_{1 / 2}$. Therefore, the results of this study performed in 20 volunteers clearly are different from the results with the St. John's wort products with high hyperforin content.

In vitro investigations have shown that hyperforin interacts with the pregnane $\mathrm{X}$ receptor, thereby leading to CYP3A induction, in a dose-dependent manner, while no similar effect was observed for hypericins or flavonoids [15-17]. In an in vivo study using oral midazolam as global CYP3A-probe substrate and six St. John's wort products with different compositions, especially hyperforin content, the extent of CYP3A induction differed among the products and was associated with hyperforin dose [19]. In that study [19], the groups that received a St. John's wort preparation with low hyperforin content had a minor 21\% AUC reduction with unchanged $\mathrm{C}_{\max }$ and $t_{1 / 2}$. This AUC reduction was not considered clinically relevant since the
$90 \%$ CI of the geometric mean ratio was within the noeffect limits. Since the study was primarily designed to investigate a dose-effect relation, the results were of an exploratory nature only regarding the individual medication groups (seven subjects per group). In the study presented here, the lack of a clinically relevant CYP3A induction by St. John's wort with low hyperforin content could be confirmed in a larger group of 20 subjects using oral midazolam as substrate.

To study the relevance of inhibition or induction by an investigational drug, oral midazolam is suggested to be the most sensitive substrate for CYP3A [22]. Regulatory authorities suggest that in case of a negative drug interaction with the most sensitive substrate, it can be presumed that less sensitive substrates would also be unaffected [22]. If study results with the most sensitive substrate indicate clinically significant interaction, additional studies with less sensitive substrates are recommended [22]. This pharmacokineticbased approach assumes that the pharmacokinetics of midazolam would be changed to a greater extent than the pharmacokinetics of other CYP3A substrates potentially coadministered in future patients. Following this concept, the expected pharmacokinetic changes of these less sensitive substrates would be lower than the mild $11 \%$ reduction in midazolam AUC observed in this study.

As reviewed by Whitten et al. [12], only three other drug-interaction studies with St. John's wort preparations with low hyperforin content have been performed. In these studies using other, less sensitive CYP3A substrates (alprazolam, ethinyl estradiol, and cyclosporine A) no interaction was found $[12,20]$. On the other hand, all 19 studies that used extracts with high hyperforin content showed relevant CYP3A induction [12]. Clinical relevance of a drug-drug interaction is ultimately determined by a change in efficacy with the need to adjust dosing.

The concept of interpretation of pharmacokinetic drugdrug interaction studies using probe substrates is based on the bioequivalence concept. If the $90 \% \mathrm{CI}$ of the geometric 
mean ratio of the pharmacokinetic parameters is within the no-effect limits, then no clinically relevant drug interaction is assumed [22]. This approach assumes that minor (up to $25 \%$ ) changes in drug exposure do not result in relevant changes of drug effect with the need for dose adjustment. In the study presented here, a mean $11 \%$ decrease was observed in midazolam exposure (used as the most sensitive CYP3A probe substrate), and the $90 \%$ CI of the geometric mean ratio was entirely within the no-effect limits. For a mean $11 \%$ decrease in exposure to a CYP3A substrate to result in a clinically relevant change in efficacy would require an extremely steep concentration-effect relationship of that CYP3A substrate. In a drug interaction study with cyclosporin A (a narrow therapeutic range CYP3A substrate) and two St. John's wort preparations, cyclosporin A dosage was adjusted only when cyclosporin A trough levels changed by more than $20 \%$ [20].

In summary, a minor significant reduction in midazolam AUC (increase in oral midazolam clearance) was found after medication with a St. John's wort powder with low hyperforin content. This mild CYP3A induction, however, is not considered clinically significant, in contrast to the well-known effect of hyperforin-rich St. John's wort preparations.

Acknowledgements We thank Jana Spaller for organizational assistance, Grit Haase for assistance in taking blood samples, and Annette Berg, Liane Krause, and Antje Schümann for processing of samples. The study was supported with funding from the following companies in Germany that have an interest in St. John's wort: Kneipp Werke, Würzburg; MCM Klosterfrau GmbH, Köln; Phytolab GmbH, Vestenbergsgreuth; Bad Heilbrunner GmbH, Bad Heilbrunn; Merz Consumer Care $\mathrm{GmbH}$, Frankfurt; GlaxoSmithKline $\mathrm{GmbH}$, Bühl; Salus-Haus, Bruckmühl.

Conflicts of interest statement: Dr. H. Sievers and Dr. R. Lehnfeld are employees of Phytolab GmbH, and Dr. B. Frank is an employee of Kneipp Werke. Both companies have an interest in St. John's wort. The other authors declared no conflict of interest.

\section{References}

1. Butterweck V (2003) Mechanism of action of St. John's wort in depression - what is known? CNS Drugs 17:539-562

2. Butterweck V, Schmidt M (2007) St. John's wort: role of active compounds for its mechanism of action and efficacy. Wien Med Wochenschr 157:356-361

3. Zanoli P (2004) Role of hyperforin in the pharmacological activities of St. John's wort. CNS Drug Rev 10:203-218

4. Butterweck V, Nahrstedt A, Evans J, Hufeisen S, Rauser L, Savage J, Popadak B, Ernsberger P, Roth BL (2002) In vitro receptor screening of pure constituents of St. John's wort reveals novel interactions with a number of GPCRs. Psychopharmacology 162:193-202

5. Melzer M, Fuhrken D, Kolkmann R (1998) Hyperforin im Johanniskraut - Hauptwirkstoff oder nur Leitsubstanz? Dtsch Apoth Ztg 138:56-62
6. Madabushi R, Frank B, Drewelow B, Derendorf H, Butterweck V (2006) Hyperforin in St. John's wort drug interactions. Eur J Clin Pharmacol 62:225-233

7. De los Reyes GC, Koda RT (2002) Determining hyperforin and hypericin content in eight brands of St. John's wort. Am J Health Syst Pharm 59:545-547

8. Draves AH, Walker SE (2003) Analysis of the hypericin and pseudohypericin content of commercially available St. John's wort preparations. Can J Clin Pharmacol 10:114-118

9. Wurglics M, Westerhoff K, Kaunzinger A, Wilke A, Baumeister A, Dressman J, Schubert-Zsilavecz M (2001) Comparison of German St. John's wort products according to hyperforin and total hypericin content. J Am Pharm Assoc 41:560-566

10. Schrader E (2000) Equivalence of St. John's wort extract (Ze 117) and fluoxetine: a randomized, controlled study in mild-moderate depression. Int Clin Psychopharmacol 15:61-68

11. Woelk H (2001) Comparison of St. John's wort and imipramine for treating depression: a randomised controlled trial. BMJ 321:536-539

12. Whitten DL, Myers SP, Hawrelak JA, Wohlmuth H (2006) The effect of St. John's wort extracts on CYP3A: a systematic review of prospective clinical trials. Br J Clin Pharmacol 62:512-526

13. Mannel M (2004) Drug interactions with St. John's wort mechanisms and clinical implications. Drug Saf 27:773-797

14. Dürr D, Stieger B, Kullak-Ublick GA, Rentsch KM, Steinert HC, Meier PJ, Fattinger K (2000) St. John's wort induces intestinal pglycoprotein/MDR1 and intestinal and hepatic CYP3A4. Clin Pharmacol Ther 68:598-604

15. Moore LB, Goodwin B, Jones SA, Wisely GB, Serabjit-Singh CJ, Willson TM, Collins JL, Kliewer SA (2000) St. John's wort induces hepatic drug metabolism through activation of the pregnane X receptor. Proc Natl Acad Sci USA 97:7500-7502

16. Wentworth JM, Agostini M, Love J, Schwabe JW, Chatterjee VKK (2000) St. John's wort, a herbal antidepressant, activates the steroid X receptor. J Endocrinol 166:R11-R16

17. Gödtel-Armbrust U, Metzger A, Kroll U, Kelber O, Wojnowski L (2007) Variability in PXR-mediated induction of CYP3A4 by commercial preparations and dry extracts of St. John's wort. Naunyn Schmiedberg's Arch Pharmacol 375:377-382

18. Komoroski BJ, Zhang S, Cai H, Hutzler JM, Frye R, Tracy TS, Strom SC, Lehmann T, Ang CYW, Cui YY, Venkataramanan R (2004) Induction and inhibition of cytochromes P450 by the St. John's wort constituent hyperforin in human hepatocyte cultures. Drug Metab Dis 32:512-518

19. Mueller SC, Majcher-Peszynska J, Uehleke B, Klammt S, Mundkowski RG, Miekisch W, Sievers H, Bauer S, Frank B, Kundt G, Drewelow B (2006) The extent of induction of CYP3A by St. John's wort varies among products and is linked to hyperforin dose. Eur J Clin Pharmacol 62:29-36

20. Mai I, Bauer S, Perloff ES, Johne A, Uehleke B, Frank B, Budde K, Roots I (2004) Hyperforin content determines the magnitude of the St. John's wort - cyclosporine drug interaction. Clin Pharmacol Ther 76:330-340

21. Arold G, Donath F, Maurer A, Diefenbach K, Bauer S, Henneicke von Zepelin HH, Friede M, Roots I (2005) No relevant interaction with alprazolam, caffeine, tolbutamide, and digoxin by treatment with a low-hyperforin St. John's wort extract. Planta Med 71:331-337

22. Huang SM, Temple R, Throckmorton DC, Lesko LJ (2007) Drug interaction studies: study design, data analysis, and implications for dosing and labeling. Clin Pharmacol Ther 81:298-304

23. Gaedcke F (1997) Johanniskraut und dessen Zubereitungen. Dtsch Apoth Ztg 137:3753-3757

24. Hölzl J, Ostrowski E (1987) Johanniskraut (Hypericum perforatum): HPLC-Analyse der wichtigen Inhaltsstoffe und deren Variabilität in einer Population. Dtsch Apoth Ztg 127:1227-1230

25. Miekisch W, Fuchs P, Berg A, Nöldge-Schomburg G, Drewelow B, Mundkowski R (2003) An improved GC/MS method for the 
determination of midazolam in human plasma [abstract]. Int J Clin Pharmacol Ther 4:560

26. U.S. Food and Drug Administration (2001) Guidance for industry - bioanalytical method validation. http://www.fda.gov/CDER/ GUIDANCE/4252fnl.htm. Accessed 15 August 2008

27. U.S. Food and Drug Administration (1994) Reviewer guidance validation of chromatographic methods. http://www.fda.gov/ CDER/GUIDANCE/cmc3.pdf. Accessed 15 August 2008

28. Ring BJ, Patterson BE, Mitchell MI, Vandenbranden M, Gillespie J, Bedding AW, Jewell H, Payne CD, Forgue ST, Ecksetin J, Wrighton SA, Phillips DL (2005) Effect of tadalafil on cytochrome P450 3A4 - mediated clearance: studies in vitro and in vivo. Clin Pharmacol Ther 77:63-75
29. Johnson BM, Song IH, Adkison KK, Borland J, Fang L, Lou Y, Berrey MM, Nafziger AN, Piscitelli SC, Bertino JS (2006) Evaluation of the drug interaction potential of aplaviroc, a novel human immunodeficiency virus entry inhibitor, using a modified Cooperstown $5+1$ cocktail. J Clin Pharmacol 46:577-587

30. Wang Z, Gorski C, Hamman MA, Huang S-M, Lesko LJ, Hall SD (2001) The effects of St. John's wort (Hypericum perforatum) on human cytochrome P450 activity. Clin Pharmacol Ther 70:317326

31. Dresser GK, Schwarz UI, Wilkinson GR, Kim RB (2003) Coordinate induction of both cytochrome P4503A and MDR1 by St. John's wort in healthy subjects. Clin Pharmacol Ther 73:41-50 